\title{
Editorial: Building and Delivering Real-World, Integrated Sustainability Solutions: Insights, Methods and Case-Study Applications
}

\author{
Nathaniel K. Newlands ${ }^{1 *}$, Tracy A. Porcelli ${ }^{2}$, Andries B. Potgieter ${ }^{3}$, Louis Kouadio ${ }^{4}$, \\ Alfredo Huete ${ }^{5}$ and Wei Guo ${ }^{6}$ \\ ${ }^{1}$ Agriculture and Agri-Food Canada, Science and Technology Branch, Summerland Research and Development Centre, \\ Summerland, BC, Canada, ${ }^{2}$ Newelli Consulting, Kelowna, BC, Canada, ${ }^{3}$ Queensland Alliance for Agriculture and Food \\ Innovation, University of Queensland, Toowoomba, QLD, Australia, ${ }^{4}$ International Centre for Applied Climate Sciences, \\ University of Southern Queensland, Toowoomba, QLD, Australia, ${ }^{5}$ School of Life Science, University of Technology Sydney, \\ Ultimo, NSW, Australia, ${ }^{6}$ Institute for Sustainable Agro-Ecosystem Services, Graduate School of Agricultural and Life \\ Sciences, The University of Tokyo, Nishitokyo, Japan
}

Keywords: adaptation, agriculture, big data, real-world, sustainability

\section{Editorial on the Research Topic}

Building and Delivering Real-World, Integrated Sustainability Solutions: Insights, Methods and Case-Study Applications

\section{OPEN ACCESS}

Edited and reviewed by:

Hayley Jane Fowler,

Newcastle University, United Kingdom

*Correspondence:

Nathaniel K. Newlands nathaniel.newlands@canada.ca

Specialty section:

This article was submitted to Interdisciplinary Climate Studies,

a section of the journal

Frontiers in Environmental Science

Received: 12 April 2019 Accepted: 10 May 2019

Published: 28 May 2019

Citation:

Newlands NK, Porcelli TA,

Potgieter AB, Kouadio L, Huete A and Guo W (2019) Editorial: Building and Delivering Real-World, Integrated Sustainability Solutions: Insights,

Methods and Case-Study

Applications. Front. Environ. Sci. 7:71. doi: 10.3389/fenvs.2019.00071
Sustaining ecosystems to deliver what people need and value, while mitigating and adapting to global climate change and extreme event impacts, presents a complex set of environmental, economic, and social challenges in ensuring resilient and sustainable food production (Fuhrer, 2007; Newlands, 2016; Whitfield et al., 2018). Regional climate trends drive variability in land productivity, soil water and nutrient availability, crop calendars, and the prevalence of pests and pathogens. Abrupt extreme events that defy clear prediction and attribution to climate trends cause catastrophic crop damage through water-logging, soil erosion, nutrient leaching, heat waves and drought. Sayer et al. (2013) proposed 10 core principles for an integrated landscape approach for reconciling agriculture, conservation, and other competing land uses. Building on these principles, the Climate Smart Landscape (CSL) approach has emerged as an integrated management strategy to address the increasing pressures on agricultural production, ecosystem conservation, rural livelihoods, and climate change mitigation/adaptation (Scheer et al., 2012; Salvini et al., 2018). The CSL approach is strengthened by a broad array of different science-based indicators, metrics, frameworks and modeling systems that enhance its capability to make more informed, integrated decisions. This approach, however, needs to incorporate big data, statistical, and artificial intelligence (AI) methodological improvements, new sensors, and remote-sensing technological advancements (Lee et al., 2010; Wolfert et al., 2017; Willcock et al., 2018). Such improvements offer more flexible monitoring, newer and/or higher-resolution data, better prediction methods, and tools for decision support.

This Research Topic aims to showcase research, development and technology (RDT) work toward devising and delivering integrated solutions that support and enhance the CSL-based approach. This Research Topic comprises 13 articles, including 10 Original Research articles, 1 Review, 1 Hypothesis and Theory article, and 1 Technology Report. State-of-the-art modeling approaches and sampling technologies are showcased. Contributed papers present new methodological/technological innovation, findings, and/or insights across four themes: (1) landscape productivity and crop suitability, (2) variable crop requirements for water and nutrients, 
(3) crop health status, phenology and phenotyping, (4) crop disease assessment and prediction under integrated pest management (IPM) and the CSL approach.

\section{LANDSCAPE PRODUCTIVITY AND CROP SUITABILITY}

Bock et al. provide a technology report on a Canadian Land Suitability Rating System (LSRS) is a rule-based algorithm integrating soil, climate, and landscape factors from accessible databases, calculating a classed suitability rating for a given landscape. It is used to support commercial field crop production, and as a spatial research tool for assessing climate change impacts. Subramanian and Crowley present a spatial-based reinforcement learning approach that uses satellite imagery to increase the predictive power of spatial dynamic models that predict, and learn better policies to manage and control spatially spreading processes. They apply this methodology in wildfire event prediction using Canadian data. Exploring landscape gradients, $\mathrm{Xu}$ et al. assess how measuring plant community assemblies along habitat severity gradients may improve our ability to understand and monitor community dynamics and species responses under future climate change.

\section{VARIABLE CROP REQUIREMENTS FOR WATER AND NUTRIENTS}

Neilsen et al. showcase a landscape-based water demand model for agricultural water use that regional water managers can use to better manage water demand and supply in response to climate change. This model considers high-resolution land use, soil, elevation, historical/future climate scenario data, a digital elevation model, sub-basins, aquifers, and socio-political jurisdictional boundaries. They use this model to explore future scenarios of climate change, and historical effects of crop production systems on irrigation water demand. From water to nutrient requirements, Guo et al. investigate aerially estimating nitrogen update from multi-angular hyperspectral data on winter wheat to improve the efficiency of remotely-based techniques for non-destructive, rapid detection of wheat nitrogen $(\mathrm{N})$ nutrient status. A novel, modified right-side peak area index (mRPA) is benchmarked against other widely used indices, and shown to have the highest predictive power. Using this index can increase accuracy in assessing crop $\mathrm{N}$ status and management. Martins et al. propose a novel methodology for tracking crop micronutrient composition over time and demonstrate it for predicting maize/corn maximum requirements under variation in nutrient uptake rates, potential evapotranspiration, and micronutrient partitioning over crop growth stages.

\section{CROP HEALTH STATUS, PHENOLOGY, AND PHENOTYPING}

Watson et al. use time-lapsed "phenocam" cameras to track the phenology and identify phenological variability of native and exotic grasses across grassland areas in Australia. Their findings indicate $\mathrm{C} 3 / \mathrm{C} 4$ species dominance to be the primary driver of phenological differences among grassland types, with the proportion of non-photosynthetic vegetation, grazing pressure, and species-dependent responses to rainfall and temperature being important biophysical drivers of grassland phenology. MODIS/Landsat satellite and field-based phenocam data were found to be in good agreement. A primary benefit of phenocam data is its higher temporal fidelity in capturing vegetation changes (i.e., increases/decreases in greenness) over periods of only 5 days, compared to coarser satellite or field measurement techniques. Using high-resolution images captured by unmanned aerial vehicles (UAVs), Guo et al. propose a two-step machine-learning based image processing method that can provide more reliable estimates of yield by detecting and counting the number of heads, than manual measurements in sorghum breeding trials, with potential for broader application in field experiments, and field production scouting operations. To better assess adaptation traits in large small-plot breeding trials, Potgieter et al. evaluate the use of a narrowband multi-spectral camera deployed on a UAV. Leaf Area Index (LAI), Normalized Difference Vegetation Index (NDVI), Enhanced Vegetation Index (EVI), and Normalized Difference Red Edge (NDRE) were evaluated. Despite variable emergence, these indices tracked canopy cover and LAI well over a large range of plant densities, with NDVI and EVI strongly correlated with plant number per plot, canopy cover, and LAI. NDRE (i.e., leaf chlorophyll content) was found to be most useful in characterizing the leaf area dynamics and senescence patterns in contrasting genotypes. In further addressing practical constraints in genomics-assisted breeding, Watanabe et al. demonstrate UAV remote sensing (with a RGB or near-infrared green and blue (NIR-GB) camera) for measuring sorghum plant height and nitrogen availability for faster and more cost-effective throughput phenotyping. For phenotyping based on root depth distributions, Wasson et al. propose a state-of-the-art Bayesian hierarchical' nonlinear mixed statistical modeling approach to estimate root depth distributions for wheat genotypes to enable breeders to select for whole root system distributions appropriate for sustainable intensification. This approach produces de-noised profiles that exhibit rigorously discernible phenotypic traits.

\section{CROP DISEASE ASSESSMENT, PREDICTION UNDER IPM AND CSL APPROACH}

Pandey et al. provide a review of soil-borne and foliar fungal diseases of mungbean (Vigna radiata var. radiata), an important legume crop in South/Southeast Asia. They review pathogen characterization, economic impacts, and integrated management practices including host resistance, fungicides, biocontrol agents, natural plant products, and cultural practices. They highlight the need for longer-term studies to validate biological methods for commercial application. For wheat (yellow) stripe rust (Puccinia striiformis f.sp. tritici) fungal disease, the greatest global pathogen threat to wheat 
production worldwide, Newlands explores the feasibility of an integrated model-based framework for predicting and controlling across large agricultural regions, using a novel spatially-explicit complex model, climate reanalysis and weather station network data.

Deploying cheaper, more accurate, and efficient technology enables the harnessing big data for use in solving sustainability challenges. With improved integrated analytical frameworks, statistical approaches, spatiallyexplicit models and indices, the CSL approach can be further developed and applied for more resilient, productive, and sustainable ecosystems. Smarter models will however require sufficient training data and operational frameworks assimilating data across a broad range of sampling platforms and data types. Agri-business will likely play an increasing role in sustainable landscape management by involving stakeholders and monitoring progress and outcomes (Salvini et al., 2018). Collectively, we can move faster to confront such complex interplay involved in translating scientific

\section{REFERENCES}

Fuhrer, J. (2007). "Chapter 7: Sustainability of crop production systems under climate change," in Agroecosystems in a Changing Climate, eds P. C. D. Newton, R. A. Carran, G. R. Edwards, and P. A. Niklaus (Boca Raton, FL: Taylor and Francis; Chapman and Hall; CRC Advances in Agroecology Series), 167-185.

Lamontagne, J. R., Reed, P. M., Marangoni, G., and Garner, G. G. (2019). Robust abatement pathways to tolerable climate futures require immediate global action. Nat. Clim. Chan. 9, 290-294. doi: 10.1038/s41558-01 9-0426-8

Lee,W. S., Alchanatis,V.,Yang,C., Hirafuji, M., Moshou, D., and Li, C. (2010). Sensing technologies for precision specialty crop production. Comput. Electron. Agric. 74, 2-33. doi: 10.1016/j.compag.2010.08.005

Newlands, N. K. (2016). Future Sustainable Ecosystems: Complexity, Risk, Uncertainty. Boca Raton, FL: Taylor and Francis (Chapman and Hall/CRC Applied Environmental Statistics Series).

Salvini, G., Dentoni, D., Ligtenberg, A., Herold, M., and Bregt, A. K. (2018). Roles and drivers of agribusiness shaping Climate-Smart landscapes: a review. Sustain. Dev. 26, 533-543. doi: 10.1002/sd.1897

Sayer, J., Sunderland, T., Ghazoul, J., Pfund, J. L., Sheil, D., Meijaard, E., et al. (2013). Ten principles for a landscape approach to reconciling agriculture, conservation, and other competing land uses. Proc. Nat. Acad. Sci. U S A. 110, 8349-8356. doi: 10.1073/pnas. 1210595110 evidence into real-world operational or actionable solutions (Lamontagne et al., 2019).

\section{AUTHOR CONTRIBUTIONS}

NN and TP co-wrote this editorial based on contributions to the Research Topic, incorporating editorial feedback provided by AP, $\mathrm{LK}, \mathrm{AH}$, and WG.

\section{ACKNOWLEDGMENTS}

We thank all authors of contributions to this Research Topic for preparing high-quality manuscripts under a tight time schedule and the reviewers for critically evaluating the papers and for further improving them with their questions, comments, and suggestions. NKN acknowledges research funding support of the Canadian Agricultural Partnership (CAP), Agriculture and Agri-Food Canada (AAFC).

Scheer, S. J., Shames, S., and Friedman, R. (2012). From climate-smart agriculture to climate-smart landscapes. Agric. Food Secur. 1:12. doi: 10.1186/2048-7010-1-12

Whitfield, S., Challinor, A. J., and Rees, R. M. (2018). Frontiers in climate smart food systems: outlining the research space. Front. Sustain. Food Syst. 2:2. doi: 10.3389/fsufs.2018.00002

Willcock, S., Martinez-López, J., Hooftman, D. A. P., Bagstad, K. J., Balbi, S., Marzo, A., et al. (2018). Machine learning for ecosystem services. Ecosyst. Serv. 33, 164-174. doi: 10.1016/j.ecoser.2018.04.004

Wolfert, S., Ge, L., Verdouw, C., and Bogaardt, M.-J. (2017). Big data in smart farming - a review. Agric. Syst. 153, 69-80. doi: 10.1016/j.agsy.2017. 01.023

Conflict of Interest Statement: The authors declare that the research was conducted in the absence of any commercial or financial relationships that could be construed as a potential conflict of interest.

Copyright (C) 2015 Her Majesty the Queen in Right of Canada. This is an open-access article distributed under the terms of the Creative Commons Attribution License (CC $B Y)$. The use, distribution or reproduction in other forums is permitted, provided the original author(s) or licensor are credited and that the original publication in this journal is cited, in accordance with accepted academic practice. No use, distribution or reproduction is permitted which does not comply with these terms. 